\title{
Structure and Agency: Shane Meadows and the New Regional Production Sectors
}

The way that things have spurted and grown in the industry in the last sort of two or three years, I'm definitely a beneficiary of all of that. Ten years previous the world probably wouldn't have accepted me in the same way, or I probably wouldn't have had as many opportunities, so I have probably landed at just the right time. Ten years ago I think I'd have been making television pieces. (Applebaum 2008)

What is it that changed in the British film industry in the mid-1990s that allowed a young, working class guy with a regional accent to develop a career making films almost exclusively set and shot in the Midlands? Part of the answer to this question must, of course, include Meadows' personal agency - his determination, his creativity, his proficiency as a director, and so on. However, while these qualities should not be underestimated they are only half the answer. While Meadows and his collaborators have utilised the opportunities and resources available to them this chapter is focussed on what created those opportunities and what this means for British cinema. As such, this chapter takes an approach to Meadows' film-making that is different to many of the other contributions to this volume by seeking to understand it within an institutional-industrial context.

The first thing to note is overall growth in the British film industry from the mid1990s. For example, in 1994 there were 32,000 people employed in the film and video industries. From a highpoint of 57,000 in 2003 , by 2009 the figure was 42,500 (Steele 2004: 14; UKFC 2010). Likewise, in 1994 total production investment in the UK was $£ 242 \mathrm{~m}$; in the 2000 s annual production spend was often twice or three times this amount and reached well over £1bn 2008-2011 (BFI 2012: 158). However, most of this growth has been in foreign-based companies, particularly Hollywood, investing in co-productions with UK-based companies in order to take advantage of tax breaks. Independent UK production - defined as films made by a UK-based 
production company that is produced wholly or partly in the UK - remained relatively constant up to 2002 and then declined steadily from 162 films in 2003 to 94 films in 2009. Furthermore, the median budgets of UK films steadily fell during the same period from $£ 3.1 \mathrm{~m}$ in 2003 to $£ 1.9 \mathrm{~m}$ in $2009 .{ }^{1}$ While growth in inward investment can help to develop film-making infrastructure and expertise it cannot alone account for the opportunities afforded to regionally-based film-makers. More important in transforming the structure of the British film industry were policy initiatives designed to encourage a regionalisation of film and media production. There was a steady growth of regional film infrastructure up to the point where the English regions could be described as significant components of the commercial film industry in Britain for the first time since circa 1914. This directly benefitted regionally-based film-makers who were more able to resist the gravitational pull of London or Los Angeles and side-step the traditional route of film school or long, London-based apprenticeships. Meadows is the most successful film-maker to emerge from this system and, as such, his career can tell us a great deal about the new regional production sectors.

Why and how did regional infrastructure develop? How did this affect Meadows' career? And what might this mean for British cinema? These are the questions that will be addressed in what follows. The first part of the chapter will outline the development of regional production sectors. From there, how this system worked in practice will be explored by mapping it onto Meadows' career. The chapter finishes by looking at the most recent changes to the structure of the British film industry. Much has changed: what prospects are there for other regionally-based filmmakers to follow in Meadows' footsteps?

\section{The Old Regional Production Sectors}


In what way is regional film production new? Since around 1914 the commercial film industry in Britain has been concentrated in London and the wider South-East, in terms of studio space and post-production facilities, production finance and company offices. While there are notable exceptions - John E. Blakely's Mancunian Films studio, ${ }^{2}$ for example - and while the regions have a long history as a location for British films, particularly within the social realist tradition, for most of its history the British film industry has been London-centric. In this context, film-making in the English regions developed outside the commercial industry under an 'arts' or cultural film paradigm supported by cultural institutions such as the British Film Institute, the Regional Arts Associations (renamed Regional Arts Boards during the 1990s) and, from the 1980s, Channel 4.

The development of regional film-making can be traced back to the regional film society movement of the 1960s, the regional Film Theatre Movement of the 1970s and, most significantly, the film workshop movement of the 1970s and 1980s. By the end of the 1980s years of campaigning and debate had resulted in a publiclyfunded regional network of workshops, organisations, groups and film-makers in cities such as Newcastle, Sheffield, Birmingham, Leeds, Liverpool, Manchester and, of course, Nottingham. While these groups were very different, they often maintained links with local communities and placed an emphasis on film and video production as a form of community and working-class empowerment and expression (see Dickinson 1999). It was this network that formed the basis of the structure of the new regional production sectors.

The 1980s also marked a change in regional audio-visual policy. Local authorities began to recognise film and media development as a key area of economic regeneration in the face of a decline in traditional manufacturing sectors. 
Regional Film Commissions were set up in order to attract outside investment from film and television companies. For local authorities eager to encourage investment in local facilities - not only production but also hotels, catering, spending on materials and so on - Screen Commissions could also help wrest film and television productions away from London and the South-East. Liverpool City Council opened a Film Liaison Office in 1989 with the support of Merseyside Television; other cities followed suit. In 1991 a national organisation - the UK Film Commission - was set up to coordinate these activities and thereby attract foreign and outside investment. Its initial budget was $£ 3.5 \mathrm{~m}$ over the first four years (Marris 1991: 29). The first regional Media Development Agency was formed in the North-East in 1984; other regions followed. For example, a Comedia feasibility study recommended that Birmingham City Council set up an Agency in 1987, a Manchester-based organisation produced a similar report in 1989 and in Nottingham the local authority began a strategy to develop the city as a media centre at around the same time (Comedia 1987; Centre for Employment Research 1989). Over the next few years Liverpool, Bristol, Leeds, Sheffield and Leicester also undertook media/cultural industries mapping exercises (Mclntyre 1996: 224). By 1991 Paul Marris could argue that:

While London and its geographical surround continue unquestionably to hold the foremost place in the UK industry, there is now a second tier, comprising Bristol, Birmingham, Cardiff, Glasgow, Leeds, Manchester and Newcastle upon Tyne, and a third including Belfast, Edinburgh, Liverpool, Nottingham, Norwich, Sheffield and Southampton. Each region of the UK has a labour and technical facilities infrastructure in the audiovisual production industry concentrated in major urban centres (Marris 1991: 27-28).

All of this increased the levels of expertise and infrastructure in the regions and by the middle of the 1990s regional cultural industries were being hyped as key drivers of employment with added bonuses such as increased tourism, higher property 
values, better quality of life and other multiplier effects. However, there was a perception of disorganisation and fragmentation across the sector.

\section{The New Regional Production Sectors}

After the election victory of New Labour in 1997, the new Department of Culture, Media and Sport launched a consultation process which led to the policy statement 'Film in England: A Development Strategy for Film and the Moving Image in the English Regions'. The report recommended the creation of nine Regional Screen Agencies (RSAs) intended to form "an integrated planning framework between the 'centre' and the regions, and between industrial and cultural priorities" (UKFC 2000: 37). The RSAs were formed through the amalgamation of the agencies that characterised regional film sectors previously: the film activities of the Regional Arts Boards, regional Media Development Agencies, Screen Commissions and other investment funds, training funds and production schemes.

So what were the features of the new regional production sectors? With increased funds the RSAs consolidated and expanded regional film activity in two man ways. Firstly, there was a massive growth in regionally-based short film schemes funded under a training and development remit. In comparison to the uneven provision that existed previously, under the UKFC each RSA administered a 'Digital Shorts' short film production scheme to identify and nurture would-be writers and directors, to develop skills and to provide a calling card to enable the transition to more ambitious work. Short film schemes were organised as a series of 'stepping stones' to facilitate a line of career progression, through the regional schemes, to the nationally administered short film schemes such as Cinema Extreme, and ultimately to feature film and television work. Digital Shorts - described by the UK Film Council 
as the "the largest digital shorts scheme ever devised" - supported the production of nearly 300 short films between 2001 and 2004, representing a substantial growth of institutionally-funded film-making in the regions (UKFC/Digital Technology Strategy Group 2003: 8).

Secondly, RSAs invested in low-budget feature film production, often utilising digital production technology, produced by small independent production companies and funded through co-production deals, most often between an RSA and a broadcaster. Although no comprehensive official data exists, these initiatives undoubtedly helped to stimulate a substantial growth in regional film-making. ${ }^{3}$

Regional film funding had two objectives: on the one hand, to "develop a sustainable UK film industry by developing the pool of creative skills and talent; developing entrepreneurial acumen and business clusters; and developing an industrial infrastructure" (Holden 2006: 37). And on the other, "to help capture the many facets of British communities":

To encourage the growth of a sense of community and identity, to identify and empower under-represented and marginalised voices, give support for different forms of distribution, and ensure diversity of access and participation (Holden 2006: 20, 17).

In this way, the new regional production sectors were given a particular role within film culture: that of representing Britain in a way that was more in line with contemporary ideas of national identity, of providing pathways into the industry for social groups traditionally excluded, of injecting some new life and vibrancy into the cinematic canon.

This regionalisation of British film production can be mapped onto Meadows' career which follows the development of the new regional production sectors very closely, in both structural and ideological terms. Meadows' career reflects and even 
pre-empts many of the features of the emerging regional sectors which became institutionalised in the funding structures of the RSAs and their partners.

\section{From Shorts to Features}

According to Kate Ogborn, Meadows appeared to be "a film-maker who came from nowhere, who proved that you didn't need to go to film school, that all you needed was a strong enough desire to make films and the gift of the gab." She continues:

The interesting aspect to Meadows' progression and development as a film-maker is that he paid no attention to the kinds of films he was supposed to make, and didn't waste time trying to second guess the successful formula for getting funding. Instead he concentrated on the resources that were available to him on his doorstep, and on telling the stories he and his friends wanted to hear (Ogborn 2000: 65).

In this way, Meadows is often characterised as an instinctive film-maker, part of a new breed drawn from outside the established film and television industries as well as the theoretically informed intelligentsia. As such a kind of origin myth surrounds his move into features, from his beginnings in home-made short films in which he played all the characters (sporting different trade-mark wigs), to SmallTime (1996), funded through ingenuity with non-professional actors improvising their performances, to the commercial and critical success of his subsequent feature films. However, Meadows' development as a film-maker also depended on the expansion of regional film-making in this period. He began making films in the mid1990s at a transitional time. Film workshops and community-based initiatives coexisted and competed with the more commercially-orientated organisations which eventually supplanted them. Film workshops active during the 1980s in Nottingham include the Other Side Video Collective, Astrodam, Isthmus Productions, the New Cinema Workshop and Nottingham Video Project, which later became Intermedia Film and Video. Intermedia, an institution with a longstanding reputation in 
Nottingham's independent film scene, ${ }^{4}$ was particularly important to Meadows' early development, lending equipment and offering support. As is well known, Meadows got his first experience through a film production scheme for the unemployed run by Intermedia in the mid-1990s and began making films with borrowed equipment in Sneinton, a predominantly working class suburb of Nottingham. Between 1994 and 1997 Meadows made some 25 short films, including the short documentary, King of the Gypsies (made in 1995 for Channel Four's 'Battered Britain' series), the awardwinning Where's the Money Ronnie? (1996) and the 'featurette' SmallTime. ${ }^{5}$

With the exception of King of the Gypsies all the films were made without direct production funding. They feature Meadows and friends and, with the exception of those mentioned above, are probably best understood as practice pieces. However, they are notable for two reasons: firstly, in that they show the development of themes and working methods that inform all Meadows subsequent feature filmmaking; and secondly that they demonstrate the willingness of funding bodies to support 'no-budget' regional film-makers on the basis of such 'homemade' work during the period.

Take SmallTime as an example. The film centres on two unemployed petty criminals, Malcolm (Matt Hand) and Jumbo (Meadows), their relationships with their respective girlfriends, Kate (Dena Smiles) and Ruby (Gena Kawecka), and how this interferes with their gang's criminal activities. The narrative is a series of episodic comic sequences: the gang engaging in various and mostly unsuccessful robberies, the domestic lives of the two couples and the social activities of the group, ending with the gang's farcical attempt to rob a "hippie shop".

The film follows the thematic concerns of Meadows' other early films: broad satirical comedy centred on a group of young, working class men and women in the 
midlands. The humour is based on an ironic detachment from the provincialism and ignorance of the characters contrasted with some of the generic motifs of a crime or gangster film. As Jumbos's opening voice over explains: “There's one thing you've got to understand, right? This ain't fucking London, this ain't even Nottingham. This is Sneinton. And all that matters in Sneinton is having a tenner in your pocket, it don't matter how you get it." In this vein the gang's activities are ludicrous parodies of provincial criminality such as stealing tins of dog food from behind a shop or robbing a car-boot sale.

SmallTime was shot over nine days with the actors, mostly made up of Meadows' friends, improvising the dialogue and scenes from a rough script. Thirteen hours of footage were then edited into the final 60 minute film. ${ }^{6}$ It was shot in the streets and houses that Meadows' and his collaborators lived in at the time, which works to authenticate the film.

Meadows has repeatedly expressed the link between his own working-class background and the themes and preoccupations of his films. For example:

Both SmallTime and Where's the Money Ronnie? are about the people I grew up with in Uttoxeter. It's as working class as it gets - full of Irish, Scots, Brummies and Stokies who came to work for JCB in the sixties. My memories of the men I grew up around were of small-time crooks, good people who had been shat on during the recession, trying to get by by skimming a bit off the top ... When I started doing filming, I used these characters (Fraser and Meadows 1998: ix-xiv).

Meadows' sense of belonging and access to the social group which form his films' subjects are thus inscribed in the production practices and stylistic choices that were developed in his early film-making. This means that despite the use of farcical comedy alongside motifs drawn from American and British popular culture, SmallTime works as an authentic representation of a regional working class community. 
SmallTime received completion funding from BFI Production to transfer it from video to $35 \mathrm{~mm}$ film for a theatrical release. It was screened at the Edinburgh film festival where, according to Ogborn, it "created a huge buzz" (Ogborn 2000: 65). At around the same time Where's the Money Ronnie? won the Channel One short film prize and put Meadows in contact with Steve Woolley, a member of the jury who encouraged him to develop a feature film project which became TwentyFourSeven. All Meadows' subsequent film and television work, in different ways, take up the themes, aesthetics and working practices developed in his early film-making. They were made on relatively low-budgets and funded by the range of agencies that invested in the emerging regional sectors in the period: Channel Four, the BBC, the British Film Institute, the UKFC and Regional Screen Agencies, specifically EM Media and Screen Yorkshire.

However, while on the surface his films demonstrate the steady development of regional production in the period, a more detailed analysis reveals this as characterised by a number of different strategies with varying levels of critical and commercial success. For example, TwentyFourSeven featured Bob Hoskins, Bruce Jones and Frank Harper with the majority of the cast made up of non-professional actors. The film was funded by the BBC and produced by Scala, a British production company specialising in low-to-medium budget British features and British-American co-productions. Along with its budget of $£ 1.5 \mathrm{~m}$, the use of actors from British film and television alongside unknowns would suggest it was intended primarily for a domestic audience but with the potential to cross over into international markets in common with other Scala productions. ${ }^{7}$ It was, however, a commercial failure, grossing just £236,000. Similarly, A Room for Romeo Brass was funded by the BBC and the National Lottery via the Arts Council. The film received a cinema release of 
just ten prints in the UK and grossed less than $£ 100,000$, making it Meadows' poorest box office return.

Once Upon a Time in the Midlands, on the other hand, can be seen as an attempt to court widespread commercial success more directly and represents a distinct change of emphasis within Meadows' established practice. It was funded by the UK Film Council and the East Midlands Media Initiative (EMMI), and produced by Film Four and EM Media, the Regional Screen Agency for the East Midlands.

Budgeted at $£ 3.5 \mathrm{~m}$ it features a cast of British stars, several of whom have appeared in Hollywood films: Roberts Carlyle, Kathy Burke, Ricky Tomlinson, Rhys Ifans and Shirley Henderson, apparently working for reduced wages on the basis of Meadows' critical reputation. Once Upon a Time in the Midlands received widespread mediocre reviews. Meadows later distanced himself from the film, putting its perceived failures down to outside interference and lack of editorial control. In particular, the commercial pressures associated with 'mainstream' casting practices forced a departure from his established production techniques during filming:

Having famous people in your films makes a difference to your box office, but it's not something l'd do regularly because it doesn't fit with how I work. It wasn't my choice in the first place to fill the cast with lots of big names ... the problem with working [with] successful actors is that it's totally different to the way I normally like to work . . . Usually we all live together for six months before I start shooting, so I'm getting to know the cast. When you're working with famous people they're so busy that they can only turn up for the odd week here and there (Wilson 2004).

The budget, casting and content of Once Upon a Time in the Midlands would suggest an attempt to appeal to a broader domestic and international audience in common with other Channel Four productions of the period and as part of an attempt to emulate the international commercial success of films like The Full Monty. ${ }^{8}$ While 
more than doubling Meadows' previous box office returns, it still made a minor impact in cinemas, grossing £496,000.

Dead Man's Shoes and This is England, were made under entirely different conditions. They represented a significant reduction in production budgets (Dead Man's Shoes cost just $£ 750,000$ to make), and feature largely unknown and nonprofessional actors, suggesting they were aimed at specialised niche audiences. Both were joint-funded by EM Media, Screen Yorkshire and Film Four, and produced by Sheffield-based Warp Films. It is these films that turned out to be Meadows' biggest commercial successes, seemingly confirming his critical reputation. ${ }^{9}$ This model informed the production of the micro-budget films Somers Town (2008) and Le Donk and Scor-zay-zee (2009), and the subsequent move into television with This is England 86 (2010) and 88 (2011).

Meadows' films demonstrate a number of different strategies for regional production during the period. These range from larger budget attempts to reach broad and even international audiences to more innovative low-budget, niche strategies. The production strategy first championed in Meadows' collaboration with Warp Films is particularly noteworthy. Concentrating on micro-to low-budget productions, Warp Films works as a regional mini-studio, integrated with distribution partners (Optimum Releasing for theatrical and DVD, Channel Four for broadcast) and regional funding agencies (EM Media and Screen Yorkshire). It represents a new kind of small, independent regionally-based film production company that was formed to take advantage of the beneficial film funding arrangements in the new regional production sectors. It is Warp Films' regional basis, vertical and horizontal integration - across finance, production, distribution and in ancillary markets such as music and publishing - and strong brand identity that provide the most successful 
business and production model for regionally-based film that emerged from the new regional production sectors. It is a particularly flexible approach that has enabled Meadows to retain creative independence while combining finance from various public and private organisations (for a discussion of this in terms of a pan-European independent film practice see Scott forthcoming). Furthermore, Warp's financing structure through EM Media and Screen Yorkshire demonstrated an increasing interregional integration as well as an increasing regional autonomy from the Londonbased industry in the period. This was mirrored by developments in other regions. For example, Digital Departures was launched by North-West Vision and Media in 2008 in Liverpool to produce low-budget, commercially-orientated feature films financed, shot and produced in the region. In a similar fashion, Northern Film and Media's Atomic Pictures supported a slate of film production by Pinball Films in the North-East from 2008 and the Bristol-based iFeatures initiative is, at the time of writing, in its second production cycle. It is too early to say what the long-term effects of these initiatives might be, but it certainly suggested a workable strategy for the future of regional film production as the first decade of the $20^{\text {th }}$ Century came to a close.

\section{Conclusion}

The period since the late-1990s has seen transformation in the structure of the film industry in Britain. There is evidence of a growing division in this period between a larger budget inward investment sector and a lower-budget, indigenous production sector that was increasingly regionally-based. Film policy initiatives directly contributed to this regionalisation. 
However, as Meadows' career demonstrates, regional film production in this period was complex, characterised by different local and national agencies, different production strategies and aimed at different markets and audiences. Meadows' career begins during a time of competing models for regional film-making. The older workshop and community film-making sector co-existed with new, more commercially orientated institutions best represented by organisations like EM Media and the other Regional Screen Agencies. Funding structures formed a 'stepping stone' system designed to identify and nurture regionally-based film-makers allowing them to progress onto more ambitious projects. This system was institutionalised in the new regional production sectors as the accepted way that regionally-based filmmakers could pursue a career. As Meadows' short films demonstrate, this was an important site for the development of working practices, thematic concerns and aesthetics and a key source of innovation in British cinema.

Mike Wayne makes the argument that in the mid-1990s "British Northerners increased their stock as a visible and viable category within the American market". He looks at films such as Brassed Off, The Full Monty, Little Voice (Mark Herman, 1998) and Billy Elliot (Stephen Daldry, 2000) as a cluster of British films that represent "the recently acquired viability within the North American market of a certain kind of British film (low budget) offering a specific regional focus within Britishness (they are all set 'up north')." For him, this demonstrates that while it is widely recognised that English heritage films are shaped according to the pressures of the international and especially American market, it is now the case that the CTNCs [Cultural Transnational Corporations] are today shaping the kinds of 'realist' films that were once thought to be the authentic representations of a national film culture (Wayne 2006: 296).

Arguably, Meadows' films show the operation of this international market on regional production sectors during the period, of which Once Upon a Time in the Midlands is 
the clearest example. However, there were also attempts to utilise and experiment with other finance and production models which demonstrate an increasing regional autonomy, particularly through organisations like EM Media and Screen Yorkshire. The most successful to date has been the low-to-micro budget production strategy adopted by Warp Films. As Meadows' work shows, these sorts of initiatives can provide a space for regional working class experience in British cinema made by film-makers with genuine roots in regional communities. This suggests one possible future for British film.

If the development of the new regional production sectors sounds very positive and optimistic there are a number of caveats that need to be mentioned. On the $26^{\text {th }}$ July 2010 the Conservative-Liberal Democrat coalition government announced that the UK Film Council was to be abolished. This was followed by the closure of the nine Regional Screen Agencies, replaced by three agencies with reduced budgets. The structures that developed over the previous fifteen or so years to support regional film-making were dismantled (for a more detailed discussion of this see Newsinger 2012).

If Meadows' career demonstrates one thing it is the continuing dependence of regional film-making on public investment in various forms. The subsidisation of regional film sectors provided a basis for low-budget indigenous production that could be maintained even if inward investment from Hollywood stopped flowing, as it periodically does. The danger is that the support for the sort of grassroots-based film-making that was central to Meadows' development declines. To take one example: Intermedia - a Nottingham institution that gave Meadows and many other local film-makers their first production experience - was effectively closed when EM Media shifted funding to another organisation. Across the sector older workshop 
groups that developed within an 'arts' remit, funding film for cultural and social

reasons and not simply as economic development, have had their funding cut or

removed altogether. Put another way, if regional film sectors provided a ladder for

first-time film-makers to climb, the ladder is now being pulled up behind them. If

Meadows is to be the first of a new breed of young, innovative, regionally-based film-

makers then these support structures need to be protected.

\section{Notes}

${ }^{1}$ Figures are taken from the UKFC 2009 Full Year Production Report (2010). This data only covers films with budgets over $£ 500,000$ and is therefore taken to be indicative of production trends as opposed to comprehensive.

2 Mancunian Films operated 1933-53 and made 25 low-budget films featuring leading Lancashire comics. See Russell, 2004.

${ }^{3}$ The UK Film Council does not record the geographical location of production companies or shooting locations of individual films. However, Nick Redfern's research suggests that between 2003 and 2007 approximately 20 percent of UK film production took place in the English regions (Redfern, 2009).

4 Intermedia has produced many short films and documentaries for various broadcasters and was the delivery company for the East-Midlands' region Digital Shorts film scheme 2002-2004. In 2002 it produced Metin Huseyin's Anita and Me, in 2003 Chris Cooke's debut feature film One for the Road, and in 2004 it co-produced Annie Watson's BAFTA nominated short Knitting a Love Song.

${ }^{5}$ SmallTime and Where's the Money Ronnie? were commercially released on video by Polygram in 1998. Thanks are due to Dave Clarke of www.shanemeadows.co.uk for providing exhaustive information on Meadows' early unavailable films and for help tracking down some of the others.

6 The improvisation can be shown through the difference between the shooting script and the finished film. The twenty five page script features extended sequences of dialogue but has no ending. The only scene to make it into the finished film in a relatively similar fashion to the script is the opening one featuring the aforementioned dog food theft. By way of explanation Meadows notes that he "was simply going to use this structure to ensure that the film wasn't a sloppy lump of shite that ran on for fourteen hours." (Fraser and Meadows, 1998: 165)

${ }^{7}$ Scala's notable production credits include Backbeat (lain Softley, 1994), Fever Pitch (David Evans, 1997), Divorcing Jack (David Caffrey, 1998), Little Voice (Mark Herman, 1999) and Last Orders (Fred Schepisi, 2002). Mike Wayne describes Scala as "a regular vehicle by which the Disney/Miramax CTNC 'plug in' to British culture and talent." (Wayne, 2006: 291) All information on production budgets, production companies, grosses and prints has been sourced and cross-checked from the BFI Film and Television Database, The Internet Movie Database, Grant (2007) and Spencer (2002). 8 The Full Monty cost $£ 2.2 \mathrm{~m}$ and grossed $£ 134 \mathrm{~m}$.

${ }^{9}$ While Dead Man's Shoes made under $£ 200000$ it reportedly went on to sell 100000 copies on DVD release. This is England grossed a healthy $£ 1.5 \mathrm{~m}$ at the UK box office.

\section{References}

Applebaum, S. (2008). "Interview with Shane Meadows." Retrieved 15th January, 2008, from http://www.britmovie.co.uk/features/applebaum/meadows00.html. BFI (2012). Statistical Yearbook 2012. London, British Film Institute. 
Centre for Employment Research (1989). The Culture Industry: The Economic Importance of the Arts and Cultural Industries in Greater Manchester. Manchester, Manchester Polytechnic.

Comedia (1987). Birmingham Audio-Visual Industry Report - Mechanisms for Intervention: Feasibility Study. London, Comedia.

Dickinson, M., Ed. (1999). Rogue Reels: Oppositional Film in Britain, 1945-90. London, BFI.

Fraser, P. and S. Meadows (1998). TwentyFourSeven (including Shane Meadows, Where's the Money Ronnie? and Left [Small Timel). Suffolk, Screen Press Books.

Holden, J. (2006). The Big Picture: The Regional Screen Agencies Building Community, Identity and Enterprise London, DEMOS.

Marris, P. (1991). UK Fllm Commission. Promoting the Industry. R. Lewis and P. Marris. London, BFI: 22-42.

McIntyre, S. (1996). Art and Industry: Regional Film and Video Policy in the UK. Film Policy: International, National and Regional Perspectives. A. Moran. London, Routledge: 215-233.

Newsinger, J. (2012). "British film policy in an age of austerity." Journal of British Cinema and Television 9(1): 133-144.

Ogborn, K. (2000). Pathways into the Industry. British Cinema of the 90s R. Murphy. London, BFI: 60-67.

Scott, J. (forthcoming). "The 'local' films of Shane Meadows." Journal of British Cinema and Television.

Steele, D. (2004). "Developing the Evidence Base for UK Film Strategy: The Research Process at the UK Film Council." Cultural Trends 13(4): 5-21.

UKFC (2000). Film in England: A Development Strategy for Film and the Moving Image in the English Regions. London, UK Film Council.

UKFC (2010). Statistical Yearbook 2010. London, UK Film Council.

UKFC/Digital Technology Strategy Group (2003). Digital Technology Strategy: An Interim Position Paper. London, UK Film Council.

Wayne, M. (2006). "The Performing Northern Working-class in British Cinema: Cultural Representation and its Political Economy." Quarterly Review of Film and Video 23(4): 287-297.

Wilson, J. (2004). "Interview with Shane Meadows." Retrieved 1st October, 2010, from http://www.leftlion.co.uk/articles.cfm?id=213. 